УДК 621.3.011.74.005

B.В. Михайленко, канд. техн. наук, доц., ORCID 0000-0002-0973-4612

Ю.М. Чуняк, ассистент, ORCID 0000-0002-4506-912X

О.С. Чарняк, студентка

Національний технічний університет України «Київський політехнічний інститут імені Ігоря Сікорського»

\title{
ДОСЛІДЖЕННЯ ПЕРЕТВОРЮВАЧА 3 ВОСЬМИЗОННИМ РЕГУЛЮВАННЯМ НАПРУГИ
}

Метою роботи є використання методу багатопараметричних функиій з використанням пакету МАТНСАD для аналізу електромагнітних процесів в електричних колах з напівпровідниковими комутаторами.

У иій статті проведено аналіз електромагнітних процесів в електричних колах напівпровідниковими з комутаторами. Створено математичну модель для аналізу електромагнітних процесів в напівпровідникових перетворювачах з широтно-імпульсним регулюванням вихідної напруги. Наведено графіки, що від ображають електромагнітні процеси у електричних колах. Статья присвячена розвитку метода багатопараметричних функиій шляхом розробки нових математичних моделей та визначення функцій і алгоритмічних рівнянь для аналізу за підсистемними складовими електромагнітних процесів у розгалуджених електричних колах з напівпровідниковими комутаторами $i$ ланками 3 синусоїдальними, постійними імпульсними напругами. Напівпровідникові коммутатори можуть виконувати високочастотне змінення структури електричних кіл і широтно-імпульсну модуляцію фазних $i$ лінійних напруг трифазної мережі електроживлення, виконуючи регулювання вихідних напруг напівпровідникових перетворювачів параметрів електричної енергії.

Ключові слова: електромагнітні процеси, вихідні напруга та струм, багатопараметричні модулюючі функції, напівпровідникові комутатори, моделювання.

Дослідження електричної енергії, а також розвиток напівпровідникової техніки дозволяють використовувати в перетворювальних установках ланку високої частоти 3 частотою переключення вентилів значно більшої від частоти змінної напруги промислової мережі. Розвиток напівпровідникової техніки дозволяє використовувати в перетворювальних установках ланку високої частоти 3 частотою переключення вентилів значно більшої від частоти змінної напруги промислової мережі. В тих випадках, коли за вимогами навантаження необхідно забезпечити його гальванічну розв'язку 3 енергетичною мережею при багатозонному регулюванні вихідної напруги, в якості проміжних структур доцільно використовувати структури перетворювачів частоти з однократною модуляцією (ПЧ з ОМ). У [1-3] показана доцільність використання структур ПЧ з ОМ в діагностичних комплексах електромеханічних систем для побудови вторинних джерел живлення з різним видом вихідної енергії. У даній роботі проводиться аналіз використання тієї ж структури в якості ланки високої частоти перетворювачів трифазної напруги в постійну напругу при підключенні силових модуляторів (CM) до фазних проводів енергетичної мережі і широтно-імпульсним регулюванням (ШІР) постійної напруги при восьмизонному керуванні. Таке з'єднання дозволяє покращити форму вхідних струмів перетворювача за рахунок відсутності в них гармонік, які кратні трьом.

Узагальнена структурна схема перетворювача показана на рис. 1. На структурній схемі позначені: $\mathrm{CM}_{A}, \mathrm{CM}_{B}, \mathrm{CM}_{C}-$ силові модулятори відповідних фазних напруг, сукупність яких представляє собою ланку високої частоти перетворювача, ВВ - високочастотний випрямляч, Н - навантаження. Кожний з СМ складається з $N$ інверторів випрямленої напруги (IBH), які включені енергетичними входами паралельно і навантажені на узгоджувальні трансформатори (TV), з'єднані вторинними обмотками послідовно.

При складанні математичної моделі перетворювача з комп'ютерною орієнтацією ії застосування використаємо метод багатопараметричних модулюючих функцій [2], який передбачає попереднє представлення алгоритмічного рівняння перетворювача. При цьому приймемо такі припущення: вхідна енергетична мережа симетрична i iï внутрішній опір дорівнює нулю, транзистори i діоди IBH представляються ідеальними ключами, узгоджувальні трансформатори в кожній з зон регулювання вихідної не мають втрат, а навантаження перетворювача має еквівалентний активно-індуктивний характер.

(C) В.В. Михайленко, Ю.М. Чуняк, О.С. Чарняк, 2018 


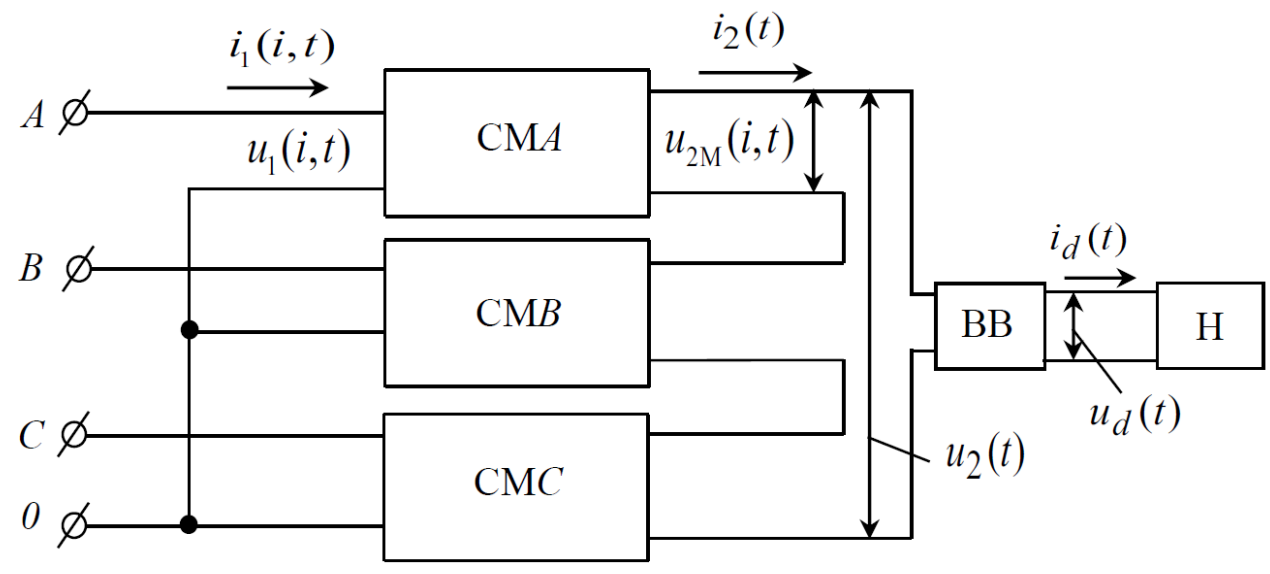

Рисунок 1 - Структурна схема перетворювача

Така структура дозволяє реалізувати багатоканальний спосіб перетворення параметрів електромагнітної енергії мережі, при якому в СМ здійснюється розгалужена модуляція миттєвих значень фазних напруг трифазної енергетичної мережі, частоти $\omega_{1}$, відповідними еквівалентними модулюючими впливами $\psi\left(\alpha_{p}, t\right)$, частоти $\omega_{2}$. В результаті такої операції на виході кожного 3 IBH формується промодульована напруга

$$
u_{2 \mathrm{M}}(p, i, t)=\frac{1}{k_{\mathrm{T}}} u_{1}(i, t) \phi(i, t) \psi\left(\alpha_{p}, t\right),
$$

де: $i=1,2,3$ - номери фазних напруг енергетичної мережі, відповідно $A, B, C ; k_{\mathrm{T}}$ - коефіцієнти трансформації узгоджувального трансформатора; $p=1,2,3, \ldots, n$ - номер зони регулювання вихідної напруги, збігається з номером інвертора СМ; $\phi(i, t)$ - функції прямокутних синусів, які співпадають за положенням в часовій області з відповідними фазних напругами мережі:

$$
\phi(i, t)=\operatorname{sign}\left\{\sin \left(\omega_{1} t-\frac{(i-1) 2 \pi}{3}\right)\right\}
$$

де: $u_{1}(i, t)$ - миттєві значення фазних напруг енергетичної мережі:

$$
u_{1}(i, t)=U_{1 m} \sin \left(\omega_{1} t-\frac{(i-1) 2 \pi}{3}\right)
$$

$U_{1 m}$ - амплітудне значення фазної напруги.

Еквівалентні модулюючі впливи подамо виразом

$$
\left.\psi\left(\alpha_{p}, t\right)=\frac{1}{2} \sum_{2} \operatorname{sign}\left(\sin \left(\omega_{2} t \pm \alpha_{p}(t)-\varphi\right)\right]\right)
$$

де $\alpha_{p}(t)$ - кути управління, за рахунок зміни яких забезпечується ШІР вихідної напруги перетворювача; $\varphi$ - початкова фаза еквівалентних модулюючих впливів.

При багатозонному регулюванні вихідної напруги перетворювача забезпечується почергово зміна кутів управління в діапазоні від 0 до $90^{\circ}$. Умови зміни кутів управління у окремих зонах подамо у вигляді: 
$\alpha_{p}(t)=0$, якщо $t<\frac{(p-1) T}{N=20} ; \alpha_{p}(t)=180^{\circ}$, якщо $t>\frac{p T}{N=20}$, а інакше $\alpha_{P}(t)=f_{\mu}(p, 20, t)$, де $f_{\mu}(p, 20, t)$ - функція, яка задає закон зміни $\alpha_{p}(t)$, яка залежить від номера зони $p$ і їх кількості

Вихідну напругу $u_{2}(t)$ ланки високої частоти перетворювача, згідно 3 його структурною організацією і з виразом (1), запишемо сумою

$$
u_{2}(t)=\sum_{p=1}^{N=8} \sum_{i=1}^{3} \frac{1}{k_{\grave{\mathrm{o}}}} u_{1}(i, t) \phi(i, t) \psi\left(\alpha_{p}, t\right),
$$

а вихідну напругу перетворювача $u_{d}(t)$ як випрямлену напругу (6) подамо виразом

$$
u_{d}(t)=\sum_{p=1}^{N=8} \sum_{i=1}^{3} \frac{1}{k_{\mathrm{o}}} u_{1}(i, t) \phi(i, t) \psi\left(\alpha_{p}, t\right) v(t),
$$

де: $v(t)$ - функція прямокутного синуса, що співпадає за часом з положенням вихідної напруги $u_{2}(t)$ ланки високої частоти перетворювача

$$
v(t)=\operatorname{sign}\left(u_{2}(t)\right)
$$

Часові діаграми вихідних напруг IBH $u_{2 \mathrm{M}}(p, i, t)$, ланки високої частоти $u_{2}(t) \mathrm{i}$ перетворювача $u_{d}(t)$, побудовані за (5) і (6) при зміні величини кута управління $\alpha_{p}$ по лінійному закону в координатах від часу $t$, подані на рис. 3 .

Для більш детального аналізу вихідної напруги перетворювача в (5) позначимо $u_{1}(i, t) \phi(i, t)=\left|u_{1}(i, t)\right| \mathrm{i}$, враховуючи (3) та (4), а також те, що в (6) $\psi\left(\alpha_{p}, t\right) v(t)=\left|\psi\left(\alpha_{p}, t\right)\right|$, алгоритмічне рівняння перепишемо у вигляді

$$
u_{d}(t)=\frac{1}{2 k_{T}} \sum_{p=1}^{N=8}\left(\sum_{i=1}^{3} \mid U_{1 m} \sin \left(\omega_{1} t-\frac{(i-1) 2 \pi}{3}|| \sum_{2} \sin n\left(\omega_{2} t \pm \alpha_{p}(t)-\varphi\right) \mid\right) .\right.
$$

Струм навантаження знайдемо, як реакцію одноконтурного $R L$-ланцюга на дію напруги (6). Для цього диференціальне рівняння, складене для вихідного контуру перетворювача, представимо в виді

$$
D(t, y)=\frac{u_{d}(t)}{L}-\frac{R}{L} y_{0},
$$

де: $y_{0}$ - визначається з початкових умов; $R$ і $L$ - відповідно активний опір і індуктивність навантаження.

Рішення (9) відносно струму навантаження визначимо числовим методом у вигляді матриці

$$
i_{d}(t)=\operatorname{rkfixed}(y, 0, k, s, D)
$$

де: $y$-вектор початкових умов; $0, k$ - часовий інтервал рішень; $s$ - кількість точок на часовому інтервалі рішень; $D$ - вектор функція диференційних рівнянь .

Часові діаграми струму навантаження в координатах вихідної напруги перетворювача і вихідного струму ланки високої частоти для восьмизонного регулювання представлені на рис. 2. 


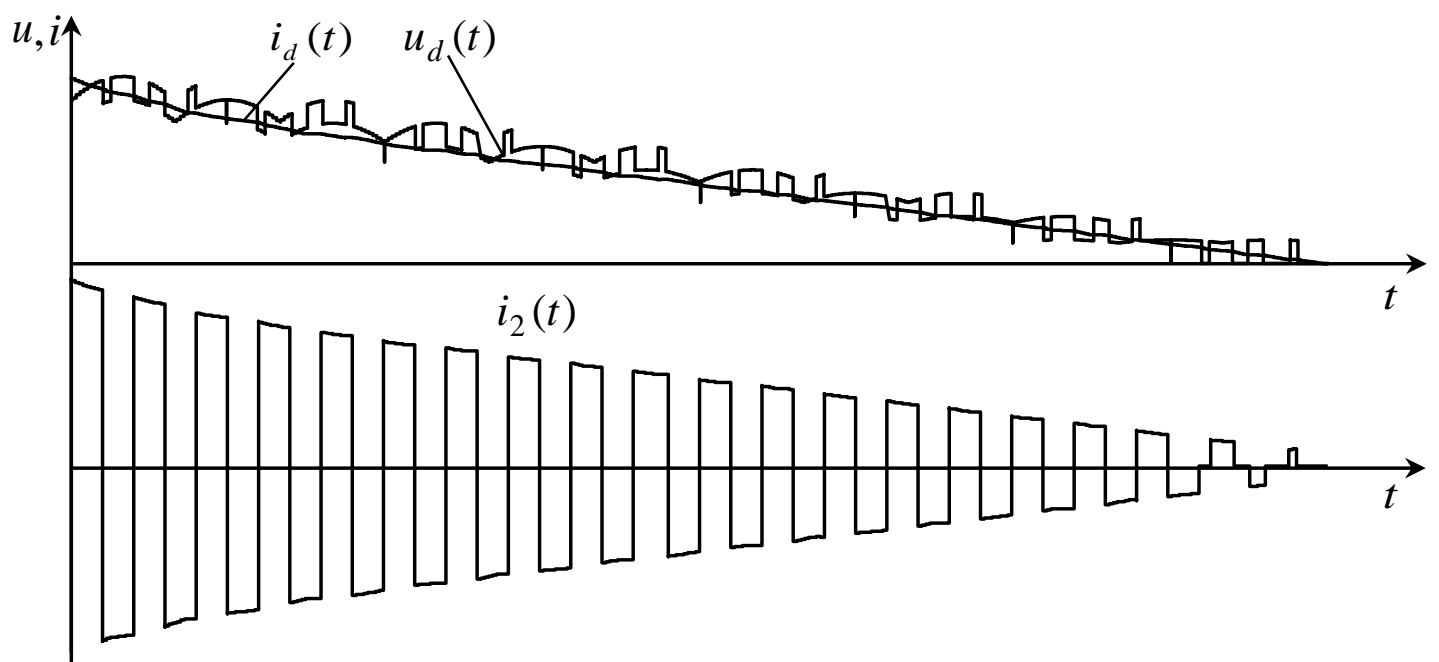

Рисунок 2 - Часові діаграми струму навантаження в координатах вихідної напруги перетворювача і вихідного струму ланки високої частоти

Враховуючи ту обставину, що на інтервалах нульових пауз (7) струм навантаження підтримується в контурі навантаження і діодів ВВ за рахунок енергії, яка запасається в індуктивності за попередні цикли роботи перетворювача і з енергетичної мережі не споживається, то для визначення вихідного струму $i_{2}(t)$ ланки високої частоти достатньо (10) перемножити на функцію (7), що має одиничну амплітуду і співпадає за часом з (6). Тоді

$$
i_{2}(t)=i_{d}(t) v(t)
$$

Для визначення вхідних струмів інверторів кожної р-ї зоні регулювання врахуємо, що $i_{2}(t)$ протікає в загальному контурі всіх СМ, утвореному послідовно з'єднаними вторинними обмотками узгоджувальних трансформаторів і приймемо до уваги алгоритмічне рівняння (6) і те, що (2), (4) i (7) $є$ функціями одиничної амплітуди.

При цьому у загальному виді

$$
i_{1}(n, i, t)=\frac{i_{2}(t) \psi\left(\alpha_{p}, t\right) \phi(i, t)}{k_{\mathrm{T}}}
$$

Для визначення вхідних СМ у всьому діапазоні регулювання вихідної напруги підсумуємо вхідні струми відповідних IBН. Враховуючи (12), загальний вираз для вхідних струмів СМ подамо у вигляді

$$
i_{1}(i, t)=\sum_{p=1}^{N=8} i_{1}(p, i, t),
$$

де: $i_{1}(p, i, t)$ - вхідні струми IВН.

Часові діаграми вхідних струмів $i$-х фаз енергетичної мережі в координатах фазних напруг, побудовані за (13), представлені на рис. 3.

Таким чином, приведені результати досліджень показують ефективність подання математичної моделі перетворювача відносно напруги навантаження, струму навантаження і струмів, що споживаються 3 вхідної мережі узагальнюючими функціями багатопараметричного виду. Узагальнюючі функції багатопараметричного виду ефективні і для інших перетворювачів модуляційного типу.

Дослідження показують ефективність використання багатопараметричних модулюючих функцій для моделювання i розрахунку електромагнітних процесів у розгалужених електричних колах напівпровідникових перетворювачів з багатозонним високочастотним широтноімпульсним регулюванням їхньої вихідної напруги при живленні RL-навантаження. 


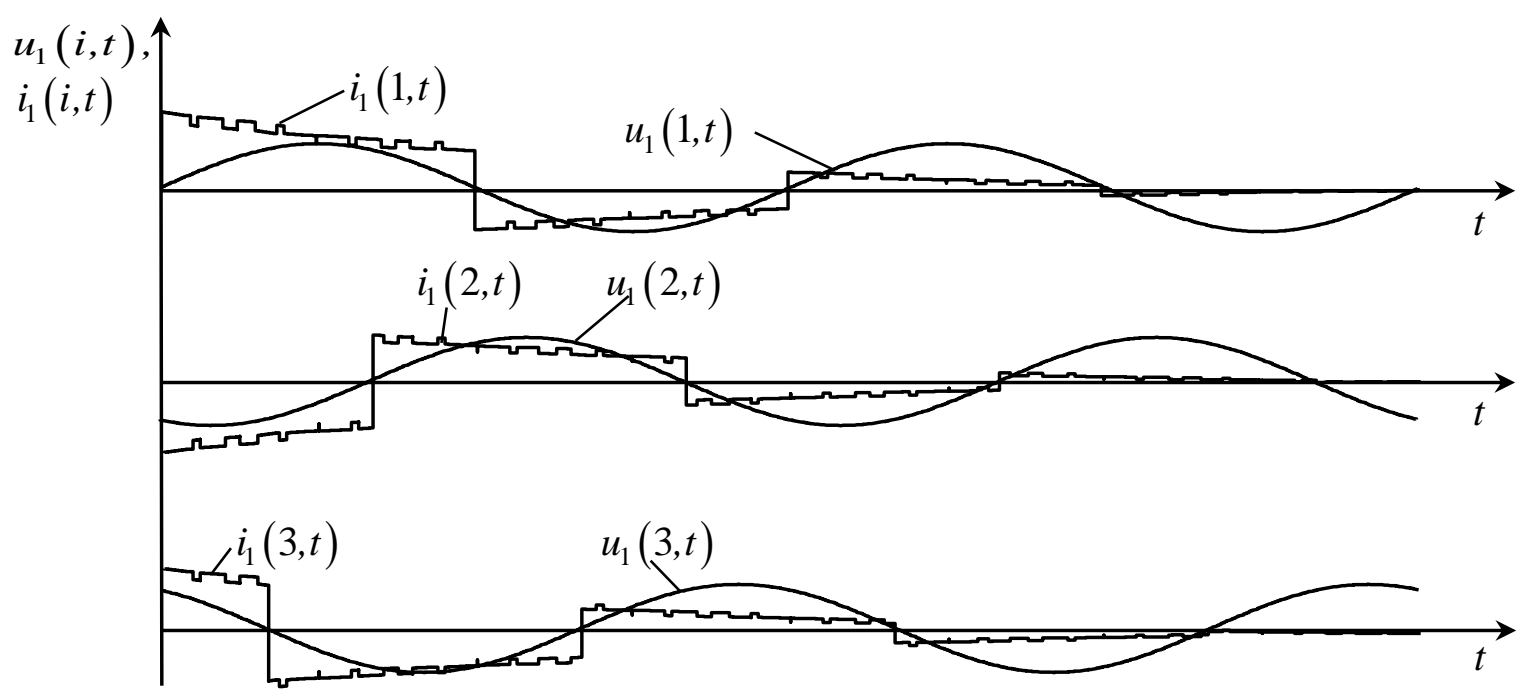

Рисунок 3- Часові діаграми вхідних струмів та напруг $i$-х фаз енергетичної мережі

\section{Висновок}

В результаті досліджень можна зробити висновок, що доцільно використовувати програмний пакет MATHCAD для аналізу електромагнітних процесів та оптимізації параметрів напівпровідникових перетворювачів. Такий підхід дозволяє зменшити нестабільність режимів у технологічному навантаженні та режимів споживання електроенергії від мережі електроживлення.

\section{Список використаної літератури}

[1] Макаренко М.П. Аналіз електромагнітних процесів у перетворювачах 3 багатозонним регулюванням вихідної напруги функціями багатопараметричного виду / М.П Макаренко, В.В. Михайленко // Технічна електродинаміка. Силова електроніка та енергоефективність - Тематичний випуск - 2002. - Ч.1. - С.19-22.

[2] Макаренко М.П. Напівпровідникові перетворювачі електромеханічних комплексів 3 покращеною електромагнітною сумісністю / М.П. Макаренко, В.В. Михайленко, А.А. Щерба, М.М. Юрченко // Вестник НТУ "Харьковский политехнический институт". "Проблемы автоматизированного электропривода. Теория и практика". - 2003.- Вып. 13. - Т. 2 - С. 213-214.

[3] Михайленко В.В. Математична модель напівпровідникового перетворювача трифазної напруги у постійну з тризонним регулюванням вихідної напруги / В.В. Михайленко, В.В. Андрійчук, Я.В. Романчук // Доповіді за матер. МНТК "Сучасні проблеми електроенерготехніки та автоматики". - Київ: Політехніка. - 2011. - С. $417-418$.

V. Mihaylenko, Cand. Sc. (Eng), Assoc. Prof., ORCID 0000-0002-0973-4612 Y. Chunyak, assistant teacher, ORCID 0000-0002-4506-912X

O. Charnyak, student National Technical University of Ukraine "Igor Sikorsky Kyiv Polytechnic Institute" STUDY OF CONVERTER WITH TWENTY ZONE REGULATION VOLTAGE

Analysis of the electromagnetic processes is organized beside this article in electric circuit with semiconductor commutator. Mathematical model is created for analysis electro-magnetic processes in semiconductor converter with width pulsed regulation of the output voltage. The broughted graphs, which reflect the electromagnetic processes in electric circuit. Method much parametric functions was used when performing calculation. The mathematical model of the converter is created for twenty zoned regulations of the output voltage. Article is devoted to the development of a method of multi-parametric modulating functions by means of working out of new mathematical models and definition of functions and the algorithmic equations for the analysis on subsystem components of electromagnetic processes in electric circuits of variable structure with sinusoidal, direct and pulsing voltage. Introduction of functions with discrete parameters in the algorithmic equations for analysis of processes in circuits with semiconductor commutators simplifies modeling on subsystem components. The mathematical model of steady-state processes and transients in electric circuits of semiconductor converters of 
modulation type with multi-channel zonal use of phase and line voltages of a three-phase network of power supplies is developed. The mathematical model of electric circuits of thyristor shapers of electro-discharge pulses for the analysis and the matching of capacitors charging modes with decrease several times of electric resistance of technological load is also created. The obtained results have a great value for development theoretical electrical engineering in a direction of simplification of calculations of electromagnetic processes in electric circuits with semi-conductor converters of the electric power. The Electromagnetic processes in electric circuit under widthpulse regulation possible to analyse with use the algorithmic equations multivariable function, which argument are a system parameters semiconductor commutator, signal of control, phases to network of the power supply and time. Introduction multivariable function with discrete parameter in algorithmic equations of the analysis formed and connecting processes in electric circuit of the variable structure allows to reflect change of this structure under system components, simplifying modeling and analysis of such processes to account of the generalization of the got equations. Except specified correlations and diagrams designed model allows to analyse forms of the output voltages and current of the separate power modules.

Keywords: electromagnetic processes, output voltage and current, multi parametric modulating functions, semi-conductor commutators, modeling.

\section{References}

[1] Makarenko M.P. The Analysis of the electromagnetic processes in converter with much zoned regulations of the output voltage function multivariable type/ M.P. Makarenko, V.V. Mihaylenko // Technicheskaia electrodinamika. Silova electronika i energoefectivnist - Thematic vypusk. - 2002. - Part 1. - P. 19-22 (Ukr.)

[2] Makarenko M.P. Semiconductor converters electromechanic complex with perfected by electric magnetic joining / M.P. Makarenko, V.V. Mihaylenko, A.A. Scherba, N.N. Yurchenko // Vesnik NTU "Kharkovskiy politehnic institute". "Problemes avtomatic electroprivoda. Theory and practice". - 2003.Issue 13. - Part 2- P. 213-214 (Ukr.

[3] Mihaylenko V.V. Mathematical model of the semiconductor converter of the three-phase voltage in constant with three zoned regulations of the output voltage / V.V. Mihaylenko, V.V. Andriychuk, Y.V. Romanchuk // Dopovidi za materialamy MNTK "Suchasni prolems electroenergetyki and avtomatic". - Kyjv: Polytechnica. 2011. - P. 417-418 (Ukr.).

B.B. Михайленко, канд. техн. наук, доц., ORCID 0000-0002-0973-4612

Ю.М. Чуняк, ассистент, ORCID 0000-0002-4506-912X

О.С. Чарняк, студентка

Национальный технический университет Украины «Киевский политехнический институт имени Игоря Сикорского»

\section{ИССЛЕДОВАНИЕ ПРЕОБРАЗОВАТЕЛЯ С ВОСЫМИЗОННЫМ} РЕГУЛИВАНИЕМ НАПРЯЖЕНИЯ

В статье проведен анализ электромагнитных процессов в электрических цепях с полупроводниковыми коммутаторами. Создана математическая модель для анализа электромагнитных процессов в полупроводниковых преобразователях с широтно-импульсным регулированием выходного напряжения. Приведены графики, которые отражают электромагнитные процессы в электрических цепях. При выполнении расчетов использовался метод многопараметрических функций. Математическая модель преобразователя создана для восьмизонного регулирования выходного напряженияПолупроводниковые коммутаторы могут осуществлять высокочастотное изменение структуры электрических цепей и широтно-импульсную модуляцию фазных и линейных напряжений трехфазной сети электропитания, реализуя регулирование выходных напряжений полупроводниковых преобразователей параметров электрической энергии.

Ключевые слова: электромагнитные процессы, выходные напряжение и ток, структура, многопараметрические модулирующие функции, полупроводниковые коммутаторы, моделирование.

Надійшла 01.01.2018

Received 01.01.2018 